\title{
Dietary Fat Selectively Alters Transport Properties of Rat Jejunum
}

\author{
A. B. R. Thomson, M. Keelan, M. T. Clandinin, and K. Walker \\ With the technical assistance of Y. McIntyre, J. Macleod, M. Tavernini, J. Terrell, and L. Poland \\ Department of Medicine, University of Alberta, Edmonton, Alberta, Canada T6G 2G3
}

\begin{abstract}
The influence of dietary fatty acid composition on intestinal active and passive transport function, brush border membrane composition, and morphology was examined in rats. Animals fed a semisynthetic diet high in saturated fatty acids demonstrated enhanced in vitro jejunal uptake of decanoic, dodecanoic, palmitic, stearic, and linoleic acid, as well as cholesterol and chenodeoxycholic and taurochenodeoxycholic acid, as compared with uptake in animals fed a semisynthetic diet high in polyunsaturated fatty acids but equivalent in total content of fat and other nutrients, or as compared with Purina chow. Feeding the saturated fatty acid diet was also associated with reduced jejunal uptake of a range of concentrations of glucose, enhanced ileal uptake of leucine, unchanged uptake of galactose, and lower uptake of decanol. The semisynthetic diets did not alter brush border membrane protein, sucrase or alkaline phosphatase activities, cholesterol, or total phospholipids, although the percentage of jejunal amine phospholipids was higher than in rats fed chow. The morphologic differences between the jejunum and ileum were abolished in animals fed the high polyunsaturated fatty acid diet; in rats fed the high saturated fatty acid diet, there was reduced mean ileal villus height, width, thickness, surface area, cell size, and villus density, as well as reduced mucosal surface area. The changes in jejunal transport were not correlated with the alterations in morphology, unstirred layer resistance, food intake, or body weight gain. It is proposed that small changes in the percentage of total dietary lipids composed of essential and nonessential fatty acids (without concurrent alterations in dietary total fat, carbohydrate, or protein) influence active and passive intestinal transport processes in the rat.
\end{abstract}

\section{Introduction}

The transport of nutrients and ion across cell membranes is an essential function of all cell types. This function involves membrane properties that are influenced by the lipid constituents of the membrane. For a variety of cell types dietary fat composition influences membrane composition and lipid dependent functions. For example, dietary fat alters the structure and function of lymphocyte membranes, liver plasma membrane, brain synaptosomes, and cardiac mitochondria (1).

There is growing evidence that transport functions of the

Address reprint requests to Dr. Thomson, Division of Gastroenterology, Department of Medicine, 8-104 Clinical Sciences Building, University of Alberta, Edmonton, Alberta, Canada T6G 2G3.

Received for publication 27 March 1985 and in revised form 16 August 1985.

J. Clin. Invest.

(C) The American Society for Clinical Investigation, Inc.

$0021-9738 / 86 / 01 / 0279 / 10 \quad \$ 1.00$

Volume 77, January 1986, 279-288 intestine are also responsive to dietary modifications (2-4). Eating diets rich in saturated fatty acids results in higher plasma cholesterol concentrations than does feeding diets containing proportionately larger amounts of polyunsaturated fatty acids (5). Variations in dietary triacylglycerol saturation alters the lipid composition and fluidity of rat intestinal plasma membranes as well as enzyme-specific activities of $p$-nitrophenyl phosphatase and $\left(\mathrm{Na}^{+}-\mathrm{K}^{+}\right)$-dependent adenosine triphosphatase (6). Although diet-induced changes in intestinal membrane phospholipids is associated with altered ion absorption, no significant changes in membrane fluidity as monitored by fluorescence anisotrophy were detected (7), and thus caution should be used in inferring changes in membrane fluidity based on lipid modulation. This study was undertaken to use a previously validated in vitro technique to compare the effect of feeding diets rich in polyunsaturated or saturated fatty acids on the jejunal uptake of cholesterol, fatty acids, decanol, bile acids, glucose, galactose, and leucine, and to attempt to correlate intestinal transport with the lipid composition of the brush border membrane (BBM) ${ }^{1}$ and with intestinal morphology.

\section{Methods}

Animals and diets. Female Wistar rats weighing 220-250 g were used. The guiding principles in the care and use of laboratory animals, approved by the Canadian Federation of Biological Societies and by the Council of the American Physiological Society, were observed in the conduct of this study. Animals were allowed ad libitum access to water and food until the morning of the study. Animals were fed one of three diets for 2-3 wk ( $17 \pm 3$ d): standard Purina Rat Chow (Ralston Purina Co., St. Louis, MO), or a semipurified diet containing $20 \%(\mathrm{wt} / \mathrm{wt})$ fat of either a high or a low polyunsaturated-to-saturated fatty acid ratio (Table I and Fig. 1). The semipurified diets were nutritionally adequate providing for all known essential nutrient requirements. The diet high in polyunsaturated fatty acids (HP) provided $\sim 22 \%$ of calories and $55 \%$ of total fatty acids (\% $\% t / w t)$ as $\mathrm{C} 18: 2 \omega 6$, whereas the diet high in saturated fatty acids (HS) provided $\sim 2 \%$ of calories and $5 \%$ of total fatty acids as C18:2 $\omega 6$. Food consumption was determined at least twice weekly. The animals were weighed at the beginning of the study as well as at the termination of the study. Intestinal weights were determined on termination of the experiment.

Probe and marker compounds. $\left[{ }^{3} \mathrm{H}\right]$ inulin $(\sim 5,000 \mathrm{~mol} \mathrm{wt})$ was used as supplied by the manufacturer (New England Nuclear, Boston, MA) to measure the adherent mucosal fluid volume. The ${ }^{14} \mathrm{C}$-labeled probes included cholic acid (CA), glycocholic acid (GCA), chenodeoxycholic acid (CDCA), taurochenodeoxycholic acid (TCDCA), decanol, D- and L-glucose, D-galactose, L-leucine, octanoic acid (fatty acid [FA] 8:0), decanoic acid (FA 10:0), dodecanoic acid (FA 12:0), myristic acid (FA 14: 0), palmitic acid (FA 16:0), stearic acid (FA 18:0), oleic acid (FA 18:1), linoleic acid (FA 18:2), linolenic acid (FA 18:3), and cholesterol. Unlabeled and ${ }^{14} \mathrm{C}$-labeled probes were supplied by Sigma Chemical Co.

1. Abbreviations used in this paper: $\mathrm{BBM}$, brush border membrane; $\mathrm{CA}$, cholic acid; CDCA, chenodeoxycholic acid; GCA, glycocholic acid; HP, high polyunsaturated fatty acid diet; HS, high saturated fatty acid diet; TCDCA, taurochenodeoxycholic acid; TDC, taurodeoxycholic acid. 
Table I. Composition of Experimental Diets

\begin{tabular}{ll}
\hline Ingredient & Concentration \\
\hline & $\mathrm{g} / \mathrm{kg}$ diet \\
Fat & 200 \\
Starch & 200 \\
Casein & 270 \\
Glucose & 207.65 \\
Non-nutritive fiber & 50 \\
Vitamin mix* & 10 \\
Mineral mix $\ddagger$ & 50.85 \\
L-methionine & 2.5 \\
Choline & 2.75 \\
Inositol & 1.25 \\
\end{tabular}

* A.O.A.C. vitamin mix, (Teklad Test Diets, Madison, WI) provided the following per kilogram of complete diet: 20,000 IU of vitamin A; $2,000 \mathrm{IU}$ of vitamin D; $100 \mathrm{mg}$ of vitamin E; $5 \mathrm{mg}$ of menadione; $5 \mathrm{mg}$ of thiamin- $\mathrm{HCl} ; 8 \mathrm{mg}$ of riboflavin; $40 \mathrm{mg}$ of pyridoxine- $\mathrm{HCl}$; $40 \mathrm{mg}$ of niacin; $40 \mathrm{mg}$ of pantothenic acid; $2,000 \mathrm{mg}$ of choline; 100 $\mathrm{mg}$ of myo-inositol; $100 \mathrm{mg}$ of $p$-aminobenzoic acid; $0.4 \mathrm{mg}$ of biotin; $2 \mathrm{mg}$ of folic acid, and $30 \mathrm{mg}$ of vitamin $B_{12}$.

¥ Bernhart Tomarelli mineral mix (General Biochemicals, Chagrin Falls, $\mathrm{OH}$ ) was modified to provide $77.5 \mathrm{mg}$ of $\mathrm{Mn}^{2+}$ and $0.06 \mathrm{mg}$ $\mathrm{Se}^{2+}$ per kilogram of complete diet.

(St. Louis, MO) and by New England Nuclear, respectively. The relative purity of the fatty acids was checked by gas chromatography, the sugars by paper chromatography, and the bile acids by thin-layer chromatography; no contaminants were detected.

Tissue preparation. Animals were anesthetized by the injection of sodium thiopentol. A 15-cm length of proximal jejunum and distal ileum was rapidly removed and rinsed gently with $50 \mathrm{ml}$ of cold saline, as described in detail elsewhere $(8,9)$. The intestine was opened along its mesenteric border, and the mucosal surface was carefully washed with cold saline to remove visible mucus and debris. Pieces of intestine were cut from the segments; the tissue was mounted as flat sheets in the incubation chambers. Preincubation chambers contained oxygenated Krebs-bicarbonate buffer $\left(\mathrm{pH} \mathrm{7.4)}\right.$ at $37^{\circ} \mathrm{C}$; the disks were preincubated for $10 \mathrm{~min}$ to allow the tissue to equilibrate at this temperature. The tissue mounted in the chambers was then transferred to other incubation beakers for specific experiments. The preincubation and incubation solutions were mixed at identical stirring rates with circular magnetic bars, and the stirring rates were precisely adjusted by means of a strobe light. Stirring rates were reported as the revolutions per minute at which the

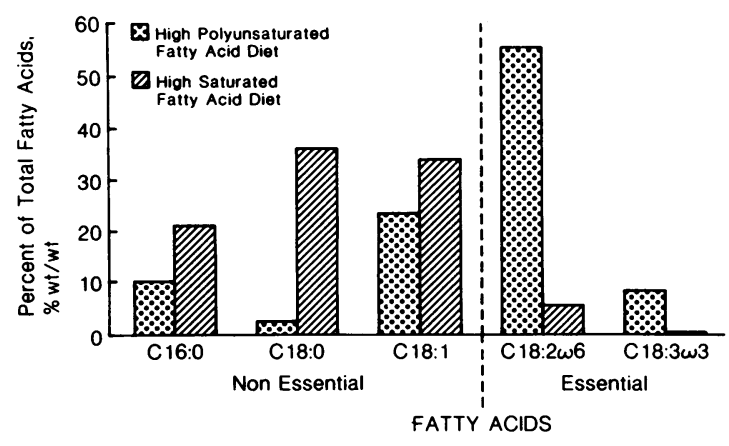

Figure 1. Fat composition of the two diets fed is shown by dotted (HP) and by hatched (HS) vertical bars. The HP was provided by using soybean oil. The HS was a blend of tallow, sunflower oil, and soybean oil. stirring bar was driven. For most studies the stirring rate of $600 \mathrm{rpm}$ was selected to achieve low effective resistance of the intestinal unstirred water layer. In one study, the uptake of decanol was examined when the bulk phase was unstirred $(0 \mathrm{rpm})$.

Determination of uptake rates. After preincubation, the chambers were transferred to other beakers containing $\left[{ }^{3} \mathrm{H}\right]$ inulin and the various ${ }^{14} \mathrm{C}$-probe molecules in oxygenated Krebs bicarbonate $\left(\mathrm{pH} \mathrm{7.4)}\right.$ ) at $37^{\circ} \mathrm{C}$. After incubation of the disks in labeled solutions for $6 \mathrm{~min}$, the experiment was terminated by removing the chamber and quickly rinsing the tissue in cold saline for $\sim 5 \mathrm{~s}$. The exposed mucosal tissue was then cut out of the chamber with a circular steel punch and was gently blotted on filter paper. For all probes except decanol, the tissue was dried overnight in an oven at $75^{\circ} \mathrm{C}$. The dry weight of the tissue was determined, the sample was saponified with $0.75 \mathrm{~N} \mathrm{NaOH}$, scintillation fluid was added, and radioactivity was determined by means of an external standardization technique to correct for variable quenching of the two isotopes. The rate of uptake of decanol was determined in a similar fashion except that Protosol (New England Nuclear) was added to the tissue; the vials were capped and the tissue was placed in an oven overnight at $56^{\circ} \mathrm{C}$. The vials were then cooled in room air, and scintillation fluid was added. From the ratio of the wet/dry weight of the jejunal tissue, the rate of uptake of the decanol was expressed as nanomoles/100 dry weight per minute (10)

Individual experiments. The method used for the preparation of micellar solutions of myristic acid, palmitic acid, stearic acid, and cholesterol has been published (11). Briefly, these lipids were solubilized in $20 \mathrm{mM}$ taurodeoxycholic acid (TDC). The concentrations of the solutes were: cholesterol, $0.05 \mathrm{mM}$; long-chain fatty acids, $0.5 \mathrm{mM}$; FA $8: 0,1 \mathrm{mM}$; FA 10:0, $0.5 \mathrm{mM}$; FA 12:0, $0.2 \mathrm{mM}$; L-glucose, $1 \mathrm{mM}$; decanol, 0.1 $\mathrm{mM}$; D-glucose, 0.5-20 mM; D-galactose, $0.5-40 \mathrm{mM}$; and L-leucine, 0.5-40 mM. The concentration of bile acids was $1 \mathrm{mM}$ (cholic acid, (CA, GCA, CDCA, and TCDCA).

$B B M$ isolation and analysis. The isolation and purification methods used to establish the marker enzymes and lipid content of the intestinal BBM has been published (12). After killing the rats, $40 \mathrm{~cm}$ each of jejunum and ileum was removed from each rat and placed into ice-cold saline. Each segment was irrigated three times with ice-cold saline and was placed on a prechilled glass plate. The mesentery was removed and the segments were opened longitudinally along the mesenteric border. The mucosal surface was blotted with lint-free tissue to remove excess moisture. The mucosal surface was removed by gently scraping with a microscope slide, placed into preweighed glass vials containing $5.0 \mathrm{ml}$ of

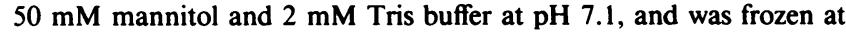
$-80^{\circ} \mathrm{C}$ for later purification of the BBM. Each vial contained the mucosal scrapings of two segments of jejunum or two segments of ileum. Sections $1 \mathrm{~cm}$ in length were taken before and after mucosal scraping, and were placed in Bouins's solution for light microscopy to determine the depth of scraping as well as to assess villus morphology.

Mucosal scrapings were transferred from the glass vial to a $250-\mathrm{ml}$ polypropylene bottle. The scrapings were homogenized in a total volume of $115 \mathrm{ml}$ of mannitol-Tris buffer using a Brinkmann Polytron (Brinkmann Instrument Co., Westbury, NY) at setting " 8 " for $15 \mathrm{~s}$. The homogenate was filtered through gauze, through a metal sieve, and through a Pharmacia $\mathbf{4 0} \mu \mathrm{m}$ Millipore filter to remove mucus and debris (Pharmacia, Inc., Piscataway, NJ; Millipore Corp. Bedford, MA). A $1.0 \mathrm{M}$ solution of $\mathrm{CaCl}_{2}$ was added to the homogenate to obtain a final concentration of $10 \mathrm{mM} \mathrm{CaCl}_{2}\left(1.0 \mathrm{ml}\right.$ of $1.0 \mathrm{M} \mathrm{CaCl}_{2} / 100 \mathrm{ml}$ of homogenate), and was then stirred gently for $10 \mathrm{~min}$ on ice with a magnetic stirrer to precipitate the subcellular components $\left(\mathrm{CaCl}_{2}\right.$ aggregates nuclei, endoplasmic reticulum, mitochondria, and basolateral membrane). The homogenate was centrifuged at $3,000 \mathrm{~g}$ for $15 \mathrm{~min}$ at $4^{\circ} \mathrm{C}$ to pellet the subcellular components. The pellet $\mathbf{P}_{1}$ was discarded. The supernatant $S_{1}$ was taken off and centrifuged at $43,700 \mathrm{~g}$ for $20 \mathrm{~min}$ at $4^{\circ} \mathrm{C}$. The supernatant $S_{2}$ was discarded. The pellet $P_{2}$ was resuspended in $30 \mathrm{ml}$ of $50 \mathrm{mM}$ mannitol-2 mM Tris-5 mM EGTA buffer at pH 7.1, and then centrifuged at $43,700 \mathrm{~g}$ for $20 \mathrm{~min}$ at $4^{\circ} \mathrm{C}$. The supernatant $\mathrm{S}_{3}$ was discarded. The pellet $P_{3}$ was resuspended in $2.0 \mathrm{ml}$ of deionized water and was sonicated (Ultrasonics cell disrupter sonicator W-375, Heat Systems- 
Ultrasonics, Inc., Plainview, NY). The sonicated $P_{3}$ preparation was layered onto $25 \mathrm{ml}$ of $40 \%$ Percoll (Pharmacia, Inc.) and was centrifuged at $43,700 \mathrm{~g}$ for $20 \mathrm{~min}$ at $4^{\circ} \mathrm{C}$. The upper fraction $(1.019-1.055 \mathrm{~g} / \mathrm{ml})$ contained the intestinal BBM. The Percoll was removed from the BBM by centrifuging the sample at $115,000 \mathrm{~g}$ for $45 \mathrm{~min}$ at $15^{\circ} \mathrm{C}$. The final BBM preparation was resuspended in the supernatant, and then aliquotted for immediate lipid extraction. Additional aliquots were stored at $-80^{\circ} \mathrm{C}$, and were subjected to marker and lipid analyses.

Protein was determined according to the method of Lowry et al. (13). The BBM markers that were assayed included sucrase (14) and alkaline phosphatase (15). In addition, $\beta$-glucuronidase $(16)$ and DNA $(17,18)$ were assayed as markers of lysosomal membranes and nuclear material, respectively. The various assay systems are linear with respect to the amount of membrane protein added to the assay system. All assays were performed at substrate concentrations that essentially yield $V_{\max }$ values. The alkaline phosphatase assay was performed using rate reaction kinetics, and therefore the linearity of the reaction was visible and was demonstrated by every sample assayed. The sucrase and $\beta$-glucuronidase assays utilize endpoint kinetics, and therefore the assays were performed with the addition of different amounts of protein to demonstrate the linearity of the reactions.

Lipid extractions of the isolated BBM were carried out immediately after preparation according to a modification of the method of Bowyer and King (19) and Folch et al. (20). The total free fatty acid content was determined on fresh BBM preparations $(21,22)$. The total bile acid content was assayed fluorimetrically on an aliquot of $\operatorname{BBM}(23,24)$. Free cholesterol and cholesterol esters were determined enzymatically from lipid extracts $(25,26)$. The total phospholipid content was assayed from lipid extracts (27), and the relative lipid composition and phospholipid composition were assayed by thin-layer chromatography $(28,29)$.

Morphology. Morphometric measurements were done on samples of jejunum and ileum which were fixed in Bouin's solution, embedded in paraffin, sectioned for light microscopy, and stained with hematoxylin and eosin using standard techniques. The method of villus surface area calculation was done as previously reported (30). Villus height, villus width at one-half height, villus bottom width, crypt depth, cell size, and the number of cells per villus were determined from longitudinal sections. Horizontal cross sections were prepared so that the second dimension of villus width, referred to here as villus thickness, could be measured at one-half villus height. The number of villi per millimeter of serosal length was measured in longitudinal and horizontal cross sections, then multiplied together to obtain the number of villi per square millimeter serosa. When this villus density was multiplied by the villus surface area, the result was the mucosal surface area, expressed as square millimeters per square millimeter of serosa. At least 10 villi were assessed per section. The following formulas were used:

Villus surface area $\left(\mu \mathrm{m}^{2} /\right.$ villus $)=(2 \times M \times H)+(2 \times M-A) \times D$

$+(2 \times D) \times\left[(A-M)^{2}+(H)^{2}\right]^{0.5} \times 1,000$,

where $H=$ villus height, $M=$ villus width at one-half height, $A=$ villus bottom width, and $D=$ villus thickness.

Mucosal surface area $\left(\mathrm{mm}^{2} / \mathrm{mm}^{2}\right.$ serosa)

$=$ number of villi $/ \mathrm{mm}^{2}$ serosa $\times$ villus surface area $\left(\mu \mathrm{m}^{2} /\right.$ villus $) / 1,000$

Expression of results. The rate of uptake, $J_{\mathrm{d}}$, was calculated after correcting the total tissue ${ }^{14} \mathrm{C}$-radioactivity for the mass of the probe molecule present in the adherent mucosal fluid (8). Uptake rates were expressed as nanomoles of the probe molecule taken up into the mucosa per $100 \mathrm{mg}$ of dry weight of tissue per minute ( $\mathrm{nmol} / 100 \mathrm{mg} \cdot \mathrm{min})$. Values obtained from different dietary groups are reported as mean \pm standard error of the mean of results observed for a minimum six animals in each group.

The statistical significance of the difference between any two means was determined using Student's $t$ test.

\section{Results}

Characteristics of animals. Food intake was greater for animals fed Purina Chow than for animals fed semipurified HP or HS (Table II). However, animals fed Chow and HS gained similar amounts of weight, whereas rats fed HP gained more weight than did animals fed Chow or HS. The wet weight of the jejunum was similar for the three dietary groups but the dry jejunal weight was significantly higher $(P<0.05)$ in animals fed HS than in those fed HP or Chow. The ratio of dry/wet jejunal weight was similar for the three dietary groups. Also, the adherent mucosal fluid volume, estimated from the $\left[{ }^{3} \mathrm{H}\right]$ inulin space, was similar for the three dietary groups.

Uptake of probe molecules. In most studies, the bulk phase was stirred at $600 \mathrm{rpm}$ to reduce effective thickness of the intestinal unstirred water layer. Tissue was incubated in radiolabeled solutions for $6 \mathrm{~min}$, and the rate of uptake of 10 solutes was determined. The rate of uptake of myristic acid (FA 14:0) was unaffected by dietary manipulation, but the rates of jejunal uptake of palmitic acid (FA 16:0), stearic acid (FA 18:0), and cholesterol were significantly higher in animals fed HS than HP or Chow (Fig. 2). The uptake of L-glucose was lower in animals fed the semipurified diets as compared with the Chow diet $(P$ $<0.05$ ), but L-glucose uptake was similar in the jejunum of animals fed HS when compared with animals fed HP.

In the second series of studies, experiments were performed in groups of animals fed either HP or HS (Fig. 3). For rats fed HS, the rates of jejunal uptake of FA 10:0, FA 12:0, and FA 18:2 were increased $(P<0.05)$ as compared with animals fed HP. In the ileum the rate of uptake of FA 10:0 and FA 12:0 was increased in animals fed HS as compared with HP $(P<0.05)$.

The rate of uptake of CA and GCA into the jejunum was similar in animals fed Chow, HS, or HP (Fig. 4). The uptake of CDCA and of TCDCA was similar in animals fed HS as compared with animals fed Chow, but the uptake of CDCA and TCDCA was lower in rats fed HP than in those fed HS. The uptake of decanol into the jejunum was significantly higher in animals fed either of the semipurified diets as compared with rats fed chow (Fig. 4). Both when the bulk phase was unstirred

Table II. Characteristics of Animals

\begin{tabular}{|c|c|c|c|}
\hline & \multirow[b]{2}{*}{ Chow } & \multicolumn{2}{|l|}{ Diet } \\
\hline & & HP & HS \\
\hline $\begin{array}{l}\text { Food consumed } \\
(g / \mathrm{rat} \cdot 2 w k)\end{array}$ & $227 \pm 9$ & $153 \pm 6^{*}$ & $172 \pm 7^{*}$ \\
\hline $\begin{array}{l}\text { Weight gain, } \\
(g / \mathrm{rat} \cdot 2 w k)\end{array}$ & $5.2 \pm 0.5$ & $7.8 \pm 0.6^{*}$ & $6.1 \pm 0.6$ \\
\hline $\begin{array}{l}\text { Adherent mucosal fluid } \\
\text { volume (liter/100 mg) }\end{array}$ & $18.0 \pm 1.2$ & $15.8 \pm 1.1$ & $17.4 \pm 1.0$ \\
\hline $\begin{array}{l}\text { Wet jejunal weight } \\
\text { ( } m g / U \text { serosal } \\
\text { surface area) }\end{array}$ & $12.4 \pm 0.7$ & $13.8 \pm 0.9$ & $11.1 \pm 0.9$ \\
\hline $\begin{array}{l}\text { Dry jejunal weight } \\
\text { ( } m g / U \text { serosal surface } \\
\text { area })\end{array}$ & $1.4 \pm 0.1$ & $2.2 \pm 0.1^{*}$ & $1.4 \pm 0.1$ \\
\hline Dry/wet jejunal weight & $0.13 \pm 0.003$ & $0.17 \pm 0.01$ & $0.16 \pm 0.005$ \\
\hline
\end{tabular}

${ }^{*} P<0.05$, Chow vs. HP, or Chow vs. HS. 


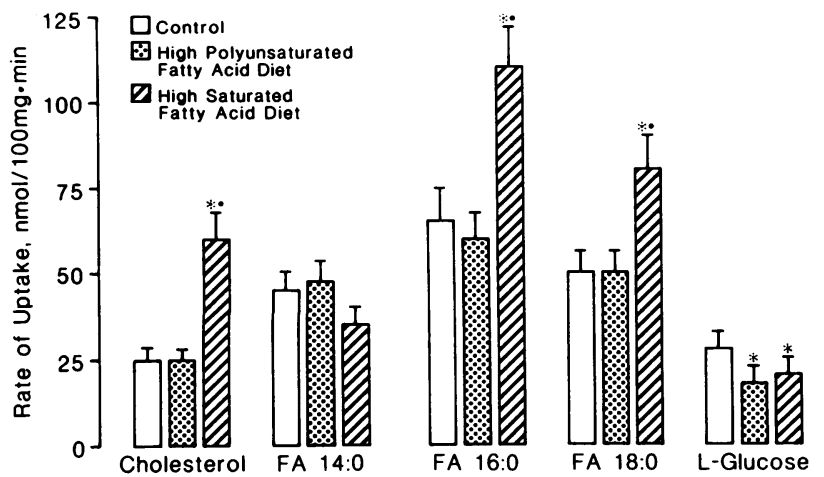

Figure 2. Effect of fatty acid composition of the diet on the jejunal uptake of cholesterol, long-chain length fatty acids, and L-glucose. The concentration of cholesterol was $0.05 \mathrm{mM}$ and the concentration of the long-chain fatty acids was $0.5 \mathrm{mM}$. These lipids were solubilized in $20 \mathrm{mM}$ TDC. The concentration of L-glucose was $1 \mathrm{mM}$, and this was studied in buffer alone. Mean \pm standard error of the mean for results from six to nine animals in each group. The bulk phase was stirred at $600 \mathrm{rpm}$ to reduce effective resistance of the intestinal unstirred water layer. An asterisk (*) indicates that the difference between the semisynthetic and the control Chow diet was statistically significant, $P$ $<0.05$. A dot $(\cdot)$ indicates that the difference between HS and HP was statistically significant, $P<0.05$.

$(0 \mathrm{rpm})$ and stirred (600 rpm), decanol uptake into the jejunum of animals fed HS was lower $(P<0.05)$ as compared with HP.

The intestinal uptake of three solutes transported by carriermediated processes was also influenced by changing the dietary fatty acid composition. In the jejunum, the rates of uptake of all five concentrations of D-glucose were lower in rats fed HS as compared with the HP, whereas a different pattern was observed in the ileum (Fig. 5). The rate of uptake of galactose into either the jejunum or the ileum was not influenced by changes in the fatty acid content of the diet (Fig. 6). In the ileum, but not in the jejunum, the rate of uptake of all concentrations of leucine was higher in animals fed HS as compared with HP (Fig. 7).

$B B M$ enzymes and lipid composition. In Chow-fed rats there was significantly lower protein content of the BBM preparations from the ileum than from the jejunum, lower alkaline phosphatase activity, lower sucrase activity, and a lower ratio of alkaline phosphatase/sucrase (Table III). These values were also lower in the ileum than in the jejunum of animals fed either HP or HS.

The semisynthetic diets influenced the BBM markers. Alkaline phosphatase activity in jejunal BBM preparations was higher but sucrase activity was lower in animals fed either HS or HP, as compared with activities in animals fed Chow. The ratio of jejunal alkaline phosphatase/sucrase activities was also higher in animals fed HP or HS as compared with rats fed Chow. The BBM alkaline phosphatase activity and the ratio of alkaline phosphatase/sucrase activities were higher in the ileum of animals fed either HP or HS than in animals fed Chow $(P<0.05)$, whereas the ileal BBM sucrase activity was lower in animals fed the semisynthetic diets as compared with those fed chow (Table III).

There were no differences in the BBM markers between animals fed HP as compared with HS.

The cholesterol content of BBM obtained from the ileum was significantly higher than those obtained from the jejunum of animals fed Chow (Table IV). The BBM ratio of total phospholipids/total cholesterol was lower $(P<0.05)$ in the ileum as compared with the jejunum only in animals fed HS (Table IV). Otherwise, there were no significant differences observed between the jejunum or the ileum, or between HP or HS as compared with the Chow diet in BBM content of total free fatty acids, total bile acids, total phospholipids, total free or cholesterol esters,

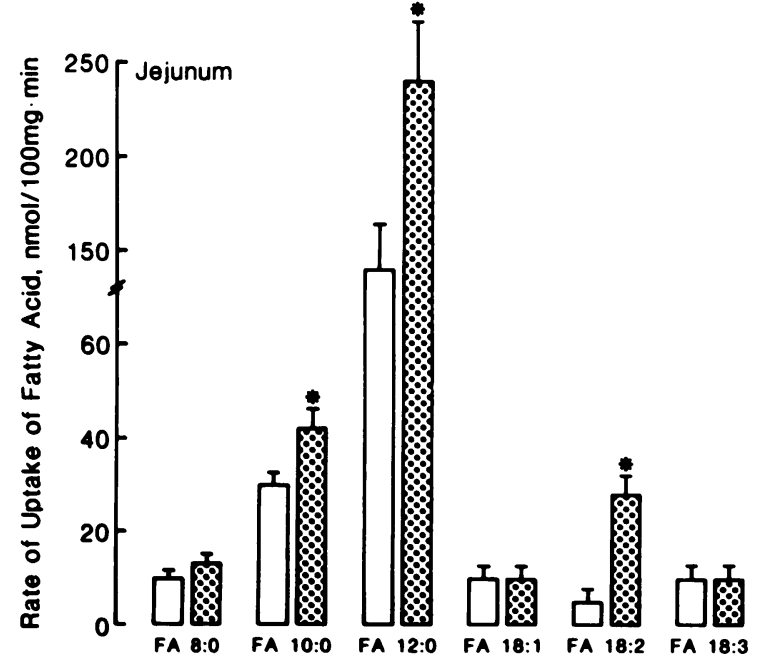

Figure 3. Effect of fatty acid composition of the diet on jejunal and ileal uptake of saturated medium-chain length and unsaturated longchain length fatty acids. Mean \pm standard error of the mean of results for a minimum of six animals in each group. The concentration of the long-chain fatty acids was $0.5 \mathrm{mM}$. The medium-chain fatty acids were studied in buffer alone whereas the long-chain fatty acids were present in a micellar solution of $20 \mathrm{mM}$ TDC. The concentrations of medium-chain fatty acids were FA 8:0, $1 \mathrm{mM}$; FA 10:0, 0.5 Mm; FA

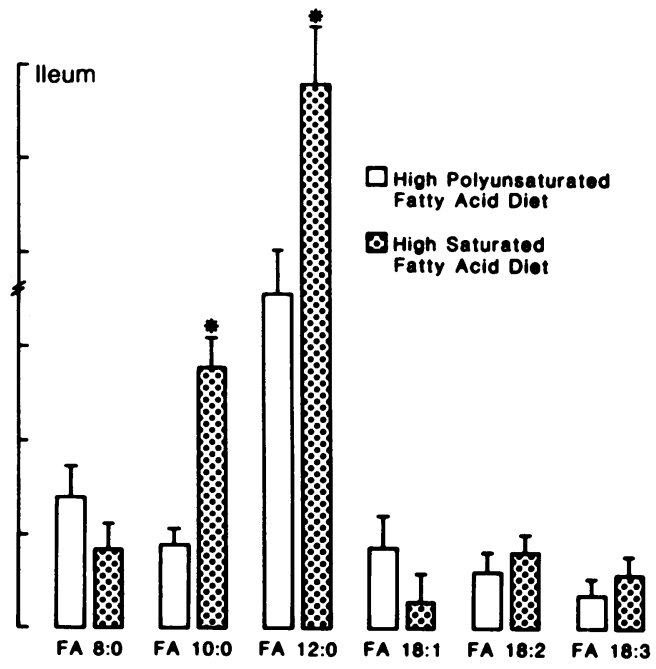

12:0, $0.2 \mathrm{mM}$. To facilitate comparison between the medium-chain length fatty acids, (FA 8:0, 10:0, and 12:0), the results were normalized to a concentration of $1 \mathrm{mM}(8)$. The bulk phase was stirred at $600 \mathrm{rpm}$ to reduce the effective resistance of the intestinal unstirred water layer. An asterisk (*) indicates that the difference between HP and the low polyunsaturated fatty acid diet was statistically significant, $P<0.05$. 


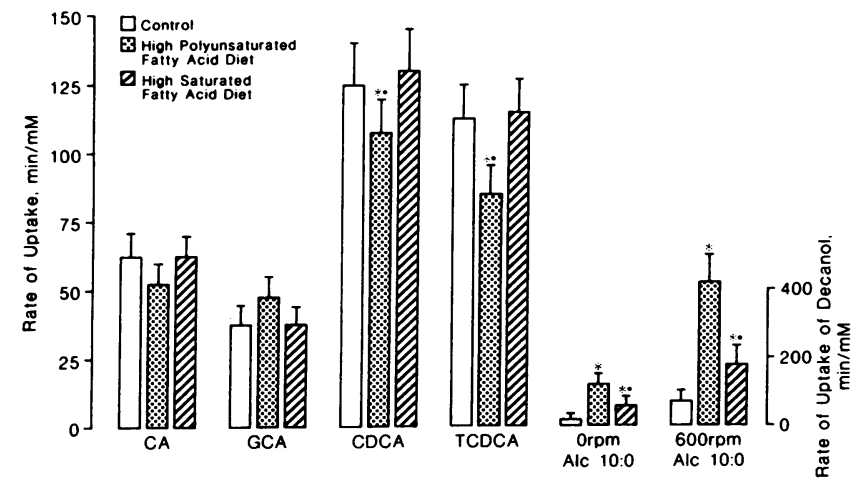

Figure 4. Effect of fatty acid composition of the diet on jejunal uptake of bile acids and decanol. The concentration of bile acids was $1 \mathrm{mM}$ and the concentration of decanol was $0.5 \mathrm{mM}$. To facilitate comparison between the bile acids and decanol, the results were normalized to a concentration of $1 \mathrm{mM}$. For bile acid uptake studies, the bulk phase was stirred at $600 \mathrm{rpm}$; for uptake of decanol the bulk phase was stirred at $0 \mathrm{rpm}$ or $600 \mathrm{rpm}$. The bulk phase was stirred at $600 \mathrm{rpm}$ to reduce the effective resistance of the intestinal unstirred water layer. An asterisk (*) indicates that the difference between the semisynthetic and the control Chow diet was statistically significant, $P<0.05$. A dot $(\cdot)$ indicates that the difference between HS and HP was statistically significant, $P<0.05$.

or the ratio of total phospholipids/total cholesterol. Similarly, there were no significant differences among Chow, HP or HS in the jejunal or ileal BBM content of phospholipid, monoglyceride, bile acid, diglyceride, triglyceride, cholesterol, free fatty acid, or cholesterol esters, when expressed as a percentage of the total lipid composition (Table V).

Differences were noted in the phospholipid composition of the BBM when comparing jejunum versus ileum (Table VI). In animals fed Chow, the BBM content of phosphatidyl inositol was lower in the ileum than in the jejunum when expressed as a percent of total phospholipid, but not when expressed as nanomoles/milligram of protein. The percent phospholipid composition of phosphatidyl ethanolamine was higher in the ileum than in the jejunum $(P<0.05)$, resulting in a higher percent amine phospholipid in the BBM of ileum as compared with jejunum in animals fed Chow (Table VII). The ratio of lecithin/

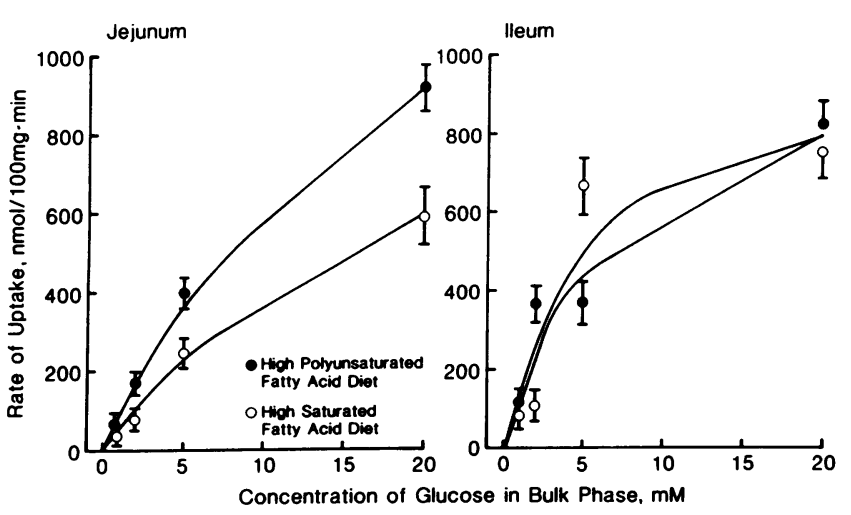

Figure 5. Effect of fatty acid composition of the diet on intestinal uptake of D-glucose. Concentration of glucose was varied from 0.5 to 20 $\mathrm{mM}$, and the bulk phase was stirred at $600 \mathrm{rpm}$. Mean \pm standard error of the mean of the results of six to nine animals in each group.

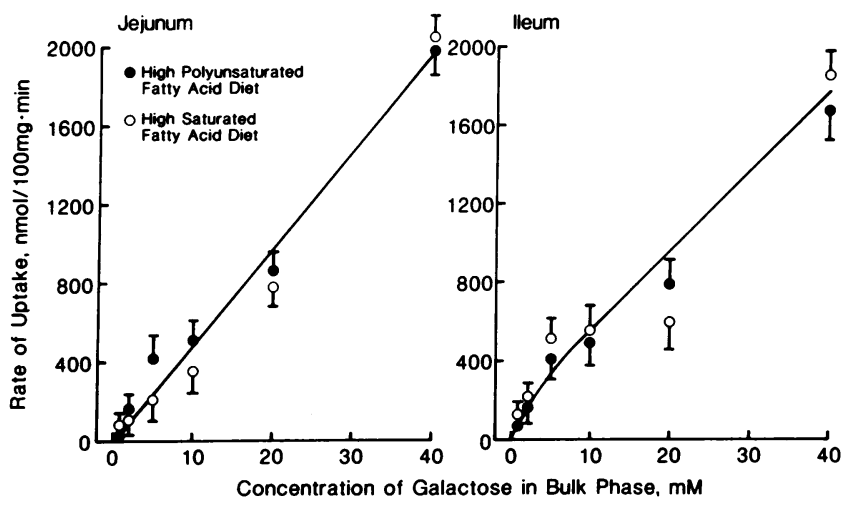

Figure 6. Effect of fatty acid composition of the diet on intestinal uptake of D-galactose. Concentration of galactose was varied from 0.5 to $40 \mathrm{mM}$, and the bulk phase was stirred at $600 \mathrm{rpm}$. Mean \pm standard error of the mean of the results of six to nine animals in each group.

cholesterol was lower in the ileum than the jejunum of animals fed Chow. In the animals fed HP, phosphatidyl serine (percent phospholipid composition as well as nanomoles/milligram of protein) was the only phospholipid significantly lower in the ileal than the jejunal BBM. In the animals fed HS, both the ratio of lecithin/cholesterol and the ratio of phosphatidyl ethanolamine/cholesterol ratios were lower $(P<0.05)$ in the ileal than the jejunal BBM.

The phospholipid profile was similar between animals fed Chow and those fed the semisynthetic diets (Table VI). The amine phospholipids (percent phospholipid composition) were higher (Table VII) in BBM from the ileum than from the jejunum of rats fed Chow, whereas the amine phospholipids nanomoles/ milligram of protein) were lower in the ileum than the jejunum of animals fed HS. These differences had no effect on the ratio of choline/amine phospholipid. The percent amine phospholipids was higher in jejunal brush border membranes of rats fed HS than in animals fed Chow $(P<0.05)$.

Morphology of intestine. In animals fed Chow, HP, or HS, the morphology of the ileum differed from the jejunum, with lower villus height, lower villus surface area, and a greater num-

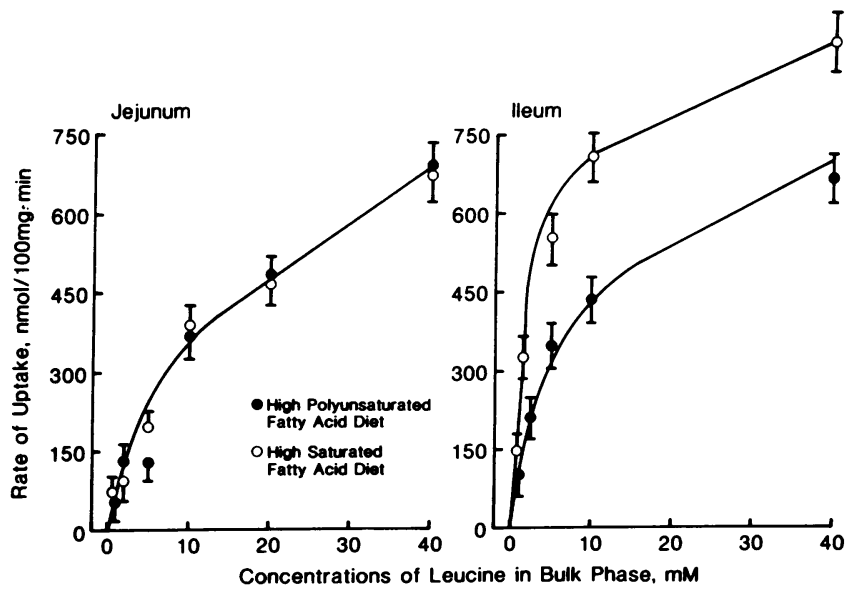

Figure 7. Effect of fatty acid composition of the diet on intestinal uptake of L-leucine. Concentration of leucine was varied from 0.5 to 40 $\mathrm{mM}$, and the bulk phase was stirred at $600 \mathrm{rpm}$. Mean \pm standard error of the mean of the results of a minimum of six animals in each group. 
Table III. Effect of Fatty Acid Composition of the Diet on BBM Markers of Rat Intestine

\begin{tabular}{|c|c|c|c|c|c|c|}
\hline \multirow[b]{2}{*}{ Membrane marker } & \multicolumn{2}{|l|}{ Chow } & \multicolumn{2}{|l|}{ HP } & \multicolumn{2}{|l|}{ HS } \\
\hline & Jejunum & Ileum & Jejunum & Ileum & Jejunum & Ileum \\
\hline \multicolumn{7}{|l|}{ Protein } \\
\hline (total mg) & $6.0 \pm 0.3$ & $3.2 \pm 0.2^{*}$ & $6.2 \pm 0.2$ & $3.6 \pm 0.2^{*}$ & $5.6 \pm 0.4$ & $3.0 \pm 0.3^{*}$ \\
\hline$(m g / g$ wet weight $)$ & $1.9 \pm 0.3$ & $1.6 \pm 0.1$ & $1.8 \pm 0.1$ & $1.7 \pm 0.1$ & $1.7 \pm 0.1$ & $1.6 \pm 0.2$ \\
\hline \multicolumn{7}{|l|}{ Alkaline phosphatase } \\
\hline (U/g protein) & $1,527 \pm 119$ & $151 \pm 35^{*}$ & $1,873 \pm 207$ & $282 \pm 36^{*} \ddagger$ & $1,830 \pm 81 \ddagger$ & $161 \pm 21^{*} \ddagger$ \\
\hline Sucrase $(U / g$ protein $)$ & $1,139 \pm 54$ & $550 \pm 42^{*}$ & $829 \pm 41 \ddagger$ & $309 \pm 23^{*} \ddagger$ & $883 \pm 35 \ddagger$ & $278 \pm 25^{*} \ddagger$ \\
\hline Alkaline phosphatase/sucrase & $1.44 \pm 0.19$ & $0.29 \pm 0.05^{*}$ & $2.04 \pm 0.30 \ddagger$ & $0.72 \pm 0.08 * \ddagger$ & $2.13 \pm 0.17 \ddagger$ & $0.66 \pm 0.33^{*} \ddagger$ \\
\hline \multicolumn{7}{|l|}{$\beta$-Glucuronidase } \\
\hline (U/g protein) & $0.28 \pm 0.03$ & $0.56 \pm 0.19$ & $0.22 \pm 0.04$ & $0.44 \pm 0.07^{*}$ & $0.36 \pm 0.05$ & $0.45 \pm 0.08$ \\
\hline DNA ( $\mu g / g$ protein) & 0 & 0 & 0 & 0 & 0 & 0 \\
\hline
\end{tabular}

* $P<0.05$, jejunum vs. ileum. $\ddagger P<0.05$, Chow vs. HP, or Chow vs. HS.

ber of villi per square millimeter of serosa (Table VIII and Fig. 8). Although villus width and mucosal surface area were lower in the ileum than in the jejunum of animals fed Chow or in animals fed HS, feeding HP removed these differences (Table VIII). Feeding the semisynthetic diets influenced villus morphology when compared with animals fed Chow: greater jejunal villus cell size, fewer cells per villus, and fewer villi per $\mathrm{mm}$ serosal length B (Table VIII). Feeding the semisynthetic diets was associated with lower ileal villus thickness, a greater number of cells per villus, and a lower number of villi per $\mathrm{mm}$ serosal length.

All aspects of jejunal morphology were similar in animals fed HP or HS (Fig. 8). In contrast, ileal morphology was influenced by the fatty acid composition of the diet: in rats fed HS as compared with HP, there was shorter ileal villus height, lower villus width but higher villus thickness, lower villus surface area, smaller villus cell size, fewer villi per millimeter of serosal length, and reduced mucosal surface area (Table VIII).

\section{Discussion}

Previous studies have shown an effect of dietary modification on passive and carrier-mediated intestinal transport (2-4). This prior work, however, represented an examination of the effect of major changes in the proportion of macronutrients on intestinal absorptive processes. In contrast, in this study the portion of the semipurified diets composed of carbohydrate, protein, and fat was unchanged (Table I); the only difference in the two semipurified diets was in the modest variation in the proportion of calories supplied as saturated or as polyunsaturated long-chain fatty acids (Fig. 1). On the high saturated fatty acid diet the rats gained weight at a similar rate as the Chow-fed animals, even though their food intake was lower (Table II). The simple maneuver of modifying the proportion of dietary fat composed of saturated versus polyunsaturated fatty acid had a profound effect on the uptake of medium- and long-chain length fatty acids, cholesterol, CDCA and TCDCA, decanol, glucose, and leucine (Fig. 2-7). Enhanced uptake of these probe molecules in the jejunum of animals fed HS did not represent a generalized and nonspecific effect, because the rates of uptake of FA 8:0, 14:0, 18:1, 18:3, CA, CDCA, and galactose were unchanged. Furthermore, the uptake of decanol was lower in animals fed the HS as compared with the HP. For the same reason, the greater jejunal uptake of the long-chain fatty acids and cholesterol was unlikely to be due to the greater mean intestinal weight of the animals fed HP (Table II), since the jejunal mucosal surface area was unchanged (Fig. 8), and more importantly in that there was a differential effect of these diets on nutrient uptake.

Table IV. Effect of Fatty Acid Composition of the Diet on BBM Lipid Content of Rat Intestine

\begin{tabular}{|c|c|c|c|c|c|c|}
\hline \multirow[b]{2}{*}{ Lipid } & \multicolumn{2}{|l|}{ Chow } & \multicolumn{2}{|l|}{ HP } & \multicolumn{2}{|l|}{ HS } \\
\hline & Jejunum & Ileum & Jejunum & Ileum & Jejunum & Ileum \\
\hline & nmol/mg protein & nmol/mg protein & $\mathrm{nmol} / \mathrm{mg}$ protein & nmol/mg protein & nmol/mg protein & nmol/mg protein \\
\hline Total free fatty acids & $410 \pm 56$ & $410 \pm 76$ & $482 \pm 57$ & $413 \pm 24$ & $428 \pm 49$ & $312 \pm 42$ \\
\hline Total bile acids & $0.9 \pm 0.3$ & $0.8 \pm 0.5$ & $0.4 \pm 0.2$ & $0.5 \pm 0.3$ & $0.8 \pm 0.4$ & $0.7 \pm 0.3$ \\
\hline Total phospholipids & $274 \pm 26$ & $256 \pm 69$ & $273 \pm 44$ & $260 \pm 47$ & $352 \pm 57$ & $235 \pm 66$ \\
\hline \multicolumn{7}{|l|}{ Cholesterol } \\
\hline Total & $221 \pm 10$ & $279 \pm 20^{*}$ & $229 \pm 23$ & $264 \pm 20$ & $221 \pm 13$ & $274 \pm 24$ \\
\hline Free & $202 \pm 15$ & $243 \pm 24$ & $202 \pm 17$ & $220 \pm 23$ & $199 \pm 14$ & $241 \pm 30$ \\
\hline Esters & $18 \pm 5$ & $36 \pm 13$ & $28 \pm 11$ & $68 \pm 21$ & $29 \pm 8$ & $38 \pm 15$ \\
\hline Total phospholipid/total cholesterol & $1.3 \pm 0.1$ & $1.0 \pm 0.2$ & $1.2 \pm 0.2$ & $1.0 \pm 0.2$ & $1.6 \pm 0.2$ & $0.9 \pm 0.2^{*}$ \\
\hline
\end{tabular}

${ }^{*} P<0.05$, jejunum vs. ileum. $P>0.05$ among Chow diet, HP, and HS. 
Table V. Effect of Fatty Acid Composition of the Diet on BBM Lipid

Expressed as a Percentage of the Total Lipid Composition of Rat Intestine

\begin{tabular}{|c|c|c|c|c|c|c|}
\hline \multirow[b]{2}{*}{ Lipid } & \multicolumn{2}{|l|}{ Chow } & \multicolumn{2}{|l|}{ HP } & \multicolumn{2}{|l|}{ HS } \\
\hline & Jejunum & Ileum & Jejunum & Ileum & Jejunum & Ileum \\
\hline PL, MG, BA & $49.8 \pm 4.1$ & $51.5 \pm 6.6$ & $49.3 \pm 4.9$ & $47.8 \pm 5.8$ & $46.9 \pm 5.6$ & $48.9 \pm 5.0$ \\
\hline DG & ND & ND & ND & ND & ND & ND \\
\hline TG & ND & ND & ND & ND & ND & ND \\
\hline Chol & $46.0 \pm 5.0$ & $45.2 \pm 5.9$ & $46.2 \pm 5.0$ & $48.0 \pm 5.6$ & $48.0 \pm 5.3$ & $48 \pm 4.2$ \\
\hline FFA & $4.0 \pm 0.5$ & $4.4 \pm 2.2$ & $4.3 \pm 1.1$ & $4.1 \pm 1.2$ & $5.0 \pm 1.1$ & $2.8 \pm 1.4$ \\
\hline $\mathrm{CE}$ & ND & ND & ND & ND & ND & ND \\
\hline
\end{tabular}

$P>0.05$ among Chow, HP, and HS. Abbreviations: PL, phospholipid; MG, monoglyceride; BA, bile acid; DG, diglyceride; TG, triglyceride; Chol, cholesterol; FFA, free fatty acid; CE, cholesterol esters; ND, not detected.

Previous dietary feeding experiments have demonstrated a greater cholesterolemic effect with saturated than with polyunsaturated diets (5). The high polyunsaturated fatty acid diet used in this study was associated with an $\sim 50 \%$ lower uptake of FA 10:0, 12:0, 16:0, 18:0, 18:2, and cholesterol (Fig. 2 and 3). However, it is unlikely that this provides an adequate explanation for the cholesterol lowering effect of polyunsaturated diets.

As expected (31), the passive jejunal uptake of the dihydroxy bile acid, CDCA, was greater than the uptake of the trihydroxy bile acid, CA (Fig. 4), but it was expected that the more polar bile acids (GCA and TCDCA) would have a lower rate of uptake than their unconjugated counterparts. The explanation for this discrepancy is unclear. The rates of uptake of CDCA and of TCDCA were lower into the jejunum of animals fed HP than HS. Current theory of cholesterol absorption (32) suggests that cholesterol is partitioned from the bile salt micelle before its uptake into the intestinal BBM, that cholesterol and bile acids are absorbed at different rates into the intestine, and that the micelle containing the cholesterol and bile acid is not absorbed intact. This study does not establish the mechanism for the enhanced uptake of the cholesterol and long-chain fatty acids and the relatively greater uptake of dihydroxy bile acid in the animals fed HS. The possibility of the villus being heterogenous with regard to the passive uptake of lipids previously has been pro-

Table VI. Effect of Fatty Acid Composition of the Diet on BBM Phospholipid Composition of Rat Intestine

\begin{tabular}{|c|c|c|c|c|c|c|}
\hline \multirow[b]{2}{*}{ Phospholipids } & \multicolumn{2}{|l|}{ Chow } & \multicolumn{2}{|l|}{ HP } & \multicolumn{2}{|l|}{ HS } \\
\hline & Jejunum & lleum & Jejunum & Ileum & Jejunum & lleum \\
\hline $\begin{array}{l}\text { Lysolecithin }(\%) \\
\text { (nmol/mg protein) }\end{array}$ & $\begin{array}{c}0.9 \pm 0.2 \\
3 \pm 1\end{array}$ & $\begin{array}{c}0.9 \pm 0.3 \\
2 \pm 1\end{array}$ & $\begin{array}{c}0.6 \pm 0.2 \\
2 \pm 1\end{array}$ & $\begin{array}{c}0.4 \pm 0.2 \\
1 \pm 1\end{array}$ & $\begin{array}{c}0.6 \pm 0.2 \\
2 \pm 1\end{array}$ & $\begin{array}{c}1.8 \pm 1.1 \\
3 \pm 1\end{array}$ \\
\hline $\begin{array}{l}\text { Sphingomyelin }(\%) \\
\quad(\text { nmol/mg protein) }\end{array}$ & $\begin{array}{c}10.5 \pm 2.4 \\
30 \pm 6\end{array}$ & $\begin{array}{c}8.0 \pm 1.2 \\
15 \pm 2\end{array}$ & $\begin{array}{l}9.4 \pm 1.2 \\
24 \pm 4\end{array}$ & $\begin{array}{l}7.7 \pm 1.6 \\
24 \pm 8\end{array}$ & $\begin{array}{c}10.0 \pm 0.8 \\
35 \pm 6\end{array}$ & $\begin{array}{c}10.8 \pm 2.2 \\
24 \pm 8\end{array}$ \\
\hline $\begin{array}{l}\text { Lecithin }(\%) \\
\qquad(\text { nmol/mg protein })\end{array}$ & $\begin{array}{c}48.3 \pm 3.9 \\
136 \pm 14\end{array}$ & $\begin{array}{c}47.4 \pm 2.3 \\
100 \pm 16\end{array}$ & $\begin{array}{c}42.9 \pm 3.7 \\
116 \pm 21\end{array}$ & $\begin{array}{c}42.2 \pm 3.4 \\
104 \pm 20\end{array}$ & $\begin{array}{c}43.9 \pm 1.6 \\
155 \pm 27\end{array}$ & $\begin{array}{c}45.6 \pm 3.6 \\
96 \pm 25\end{array}$ \\
\hline $\begin{array}{l}\text { Phosphatidyl serine }(\%) \\
\text { (nmol/mg protein) }\end{array}$ & $\begin{array}{c}1.6 \pm 0.8 \\
5 \pm 3\end{array}$ & $\begin{array}{c}0.3 \pm 0.3 \\
1 \pm 1\end{array}$ & $\begin{array}{c}2.6 \pm 0.5 \\
8 \pm 2\end{array}$ & $\begin{array}{c}0.4 \pm 0.3^{*} \\
1 \pm 1^{*}\end{array}$ & $\begin{array}{c}2.3 \pm 0.7 \\
9 \pm 4\end{array}$ & $\begin{array}{l}1.2 \pm 0.7 \\
36 \pm 2\end{array}$ \\
\hline $\begin{array}{l}\text { Phosphatidyl inositol (\%) } \\
\text { (nmol/mg protein) }\end{array}$ & $\begin{array}{c}13.8 \pm 3.3 \\
40 \pm 11\end{array}$ & $\begin{array}{l}6.0 \pm 1.7^{*} \\
14 \pm 6\end{array}$ & $\begin{array}{c}10.2 \pm 1.8 \\
29 \pm 8\end{array}$ & $\begin{array}{l}8.1 \pm 1.8 \\
21 \pm 8\end{array}$ & $\begin{array}{c}11.4 \pm 1.7 \\
41 \pm 11\end{array}$ & $\begin{array}{l}7.1 \pm 1.8 \\
15 \pm 7\end{array}$ \\
\hline $\begin{array}{l}\text { Phosphatidic acid (\%) } \\
\text { (nmol/mg protein) }\end{array}$ & $\begin{array}{l}0.2 \pm 0.2 \\
0.2 \pm 0.2\end{array}$ & $\begin{array}{l}0.2 \pm 0.2 \\
0.6 \pm 0.7\end{array}$ & $\begin{array}{l}\text { ND } \\
\text { ND }\end{array}$ & $\begin{array}{l}\text { ND } \\
\text { ND }\end{array}$ & $\begin{array}{l}0.1 \pm 0.1 \\
0.3 \pm 0.4\end{array}$ & $\begin{array}{l}0.5 \pm 0.6 \\
1.3 \pm 1.5\end{array}$ \\
\hline $\begin{array}{l}\text { Lysophosphatidyl ethanolamine (\%) } \\
\text { (nmol/mg protein) }\end{array}$ & $\begin{array}{l}7.4 \pm 0.9 \\
22 \pm 4\end{array}$ & $\begin{array}{c}6.6 \pm 1.4 \\
16 \pm 2\end{array}$ & $\begin{array}{l}8.1 \pm 1.0 \\
22 \pm 4\end{array}$ & $\begin{array}{c}6.3 \pm 1.2 \\
15 \pm 4\end{array}$ & $\begin{array}{l}8.4 \pm 1.5 \\
28 \pm 7\end{array}$ & $\begin{array}{l}5.9 \pm 1.4 \\
14 \pm 6\end{array}$ \\
\hline $\begin{array}{l}\text { Phosphatidyl ethanolamine (\%) } \\
\text { (nmol/mg protein) }\end{array}$ & $\begin{array}{c}16.9 \pm 3.4 \\
50 \pm 13\end{array}$ & $\begin{array}{c}29.0 \pm 2.6^{*} \\
66 \pm 18\end{array}$ & $\begin{array}{c}25.8 \pm 3.7 \\
71 \pm 18\end{array}$ & $\begin{array}{c}29.5 \pm 4.5 \\
71 \pm 21\end{array}$ & $\begin{array}{c}22.7 \pm 1.6 \\
73 \pm 14\end{array}$ & $\begin{array}{c}25.9 \pm 4.2 \\
46 \pm 10\end{array}$ \\
\hline Lecithin/cholesterol & $0.6 \pm 0.1$ & $0.4 \pm 0.1^{*}$ & $0.5 \pm 0.1$ & $0.5 \pm 0.1$ & $0.7 \pm 0.1$ & $0.4 \pm 0.1^{*}$ \\
\hline Phosphatidyl ethanolamine/cholesterol & $0.2 \pm 0.1$ & $0.2 \pm 0.1$ & $0.3 \pm 0.1$ & $0.3 \pm 0.1$ & $0.3 \pm 0.1$ & $0.2 \pm 0.2^{*}$ \\
\hline
\end{tabular}

ND, not detected. $P>0.05$ Chow vs. HP, or Chow vs. HS. ${ }^{*} P<0.05$, jejunum vs. ileum. 
Table VII. Effect of Fatty Acid Composition of the Diet on BBM Choline and Amine Phospholipid Composition of Rat Intestine

\begin{tabular}{|c|c|c|c|c|c|c|}
\hline \multirow[b]{2}{*}{ Phospholipid } & \multicolumn{2}{|l|}{ Chow } & \multicolumn{2}{|l|}{ HP } & \multicolumn{2}{|l|}{ HS } \\
\hline & Jejunum & Ileum & Jejunum & Ileum & Jejunum & lleum \\
\hline $\begin{array}{l}\text { Choline phospholipid (\%) } \\
\text { (nmol/mg protein) }\end{array}$ & $\begin{array}{c}59.8 \pm 5.8 \\
169 \pm 18\end{array}$ & $\begin{array}{c}56.4 \pm 3.4 \\
148 \pm 35\end{array}$ & $\begin{array}{c}53.1 \pm 4.9 \\
142.3 \pm 25.5\end{array}$ & $\begin{array}{c}54.6 \pm 6.2 \\
128 \pm 28\end{array}$ & $\begin{array}{c}54.6 \pm 2.3 \\
193 \pm 33\end{array}$ & $\begin{array}{c}58.3 \pm 5.9 \\
122 \pm 33\end{array}$ \\
\hline $\begin{array}{l}\text { Amine phospholipid }(\%) \\
\text { (nmol/mg protein) }\end{array}$ & $\begin{array}{c}26.0 \pm 3.4 \\
77 \pm 15\end{array}$ & $\begin{array}{c}36.0 \pm 2.3^{*} \\
96 \pm 21\end{array}$ & $\begin{array}{c}35.6 \pm 3.5 \\
97 \pm 20\end{array}$ & $\begin{array}{c}35.7 \pm 4.5 \\
86 \pm 25\end{array}$ & $\begin{array}{l}32.9 \pm 0.8 \ddagger \\
115 \pm 18\end{array}$ & $\begin{array}{r}33.0 \pm 4.3 \\
64 \pm 18^{*}\end{array}$ \\
\hline $\begin{array}{l}\text { Choline phospholipid/ } \\
\text { Amine phospholipid }\end{array}$ & $2.6 \pm 0.5$ & $1.6 \pm 0.2$ & $1.7 \pm 0.4$ & $1.9 \pm 0.7$ & $1.7 \pm 0.1$ & $2.2 \pm 0.7$ \\
\hline
\end{tabular}

${ }^{*} P<0.05$, jejunum vs. ileum. $\ddagger P<0.05$, Chow vs. HP, or Chow vs. HS.

posed (33). The differential effect of dietary feeding on the uptake of fatty acids (Fig. 2 and 3 ) also suggests that a different portion of the villus may be used for the uptake of the various lipid molecules.

Analysis of the jejunal and ileal BBM indicated that feeding HS had no effect on the BBM content of lipid apart from an increased percentage of the total phospholipids appearing as amine phospholipids (Table VII). Increasing the dietary content of FA 16:0, FA 18:0, and FA 18:1 (HS) was associated with an increased uptake of FA 16:0 and FA 18:0 (Fig. 2 and 3), yet the feeding of decreased amounts of FA 18:2 and FA 18:3 (Fig. 1) was associated with increased jejunal uptake of FA 18:2 but no change in the uptake of 18:3 (Fig. 3). A possible role of dietary lipids in the changes in BBM occurring after intestinal resection has been proposed (34). Possible alterations of the phospholipid fatty acyl chains may be related to the permeability changes observed with the two semisynthetic diets (6). It has been suggested that alterations in the fatty acid composition of the constituent membrane phospholipids may be related to changes in membrane function $(35,36)$. Dietary fat has been shown to influence the alteration of the physical properties of membrane lipids from heart and brain $(37,38)$. Variations in dietary triacylglycerol saturation alter the lipid composition and fluidity of rat intestinal plasma membranes (6); although the fatty acyl constituents of the intestinal brush border membrane were not measured in this study, it is likely that the altered active and passive intestinal transport properties were due to changes in the fatty acyl constituents in the bulk and/or boundary lipids.

The effective resistance of the intestinal unstirred water layer is a major barrier to uptake of highly permeant molecules such as long-chain fatty acids and cholesterol (39). The lower uptake of decanol into the jejunum, under conditions of no stirring $(0$ $\mathrm{rpm}$ ) or moderate stirring (600 rpm) of the bulk phase (Fig. 4), indicates a higher resistance of the unstirred water layer in animals fed HS. The higher unstirred layer resistance in HS would retard the uptake of lipid molecules. The uptake of cholesterol and long-chain fatty acids was in fact greater, rather than less, in the animals fed HS (Fig. 2 and 3). Thus the greater uptake of these probes in HS must have been due to a greater permeability of the membrane toward the medium- and long-chain length fatty acids and cholesterol, rather than due to differences in the effective resistance of the intestinal unstirred water layer.

The effect of changes in the fatty acid content of the diet on intestinal absorption was not limited to passive uptake (Fig. 24). Indeed, marked differences were noted in carrier-mediated uptake in animals fed HP vs. those fed HS. The influence of these diets depended upon the probe and the site of absorption studied: galactose uptake was similar in rats fed either semisyn-

Table VIII. Effect of Fatty Acid Composition of the Diet on Rat Intestinal Morphology

\begin{tabular}{|c|c|c|c|c|c|c|}
\hline \multirow[b]{2}{*}{ Morphologic parameter } & \multicolumn{2}{|l|}{ Chow } & \multicolumn{2}{|l|}{ HP } & \multicolumn{2}{|l|}{ HS } \\
\hline & Jejunum & Ileum & Jejunum & Ileum & Jejunum & lleum \\
\hline Crypt depth $(\mu m)$ & $92 \pm 5$ & $73 \pm 4$ & $98 \pm 7$ & $70 \pm 5$ & $88 \pm 4$ & $79 \pm 4$ \\
\hline Villus height $(\mu m)$ & $417 \pm 12$ & $189 \pm 13^{*}$ & $387 \pm 44$ & $281 \pm 11 * \ddagger$ & $434 \pm 23$ & $173 \pm 4 * \S$ \\
\hline Villus width, one-half height $(\mu m)$ & $139 \pm 5$ & $110 \pm 8^{*}$ & $139 \pm 12$ & $192 \pm 9 \ddagger$ & $122 \pm 4 \ddagger$ & $99 \pm 44 * \S$ \\
\hline Villus thickness $(\mu m)$ & $397 \pm 31$ & $430 \pm 24$ & $531 \pm 43 \ddagger$ & $244 \pm 19^{*} \ddagger$ & $480 \pm 28$ & $347 \pm 23^{*} \ddagger \S$ \\
\hline Villus surface area $\left(\mu \mathrm{m}^{2} / v i l l u s\right)$ & $499 \pm 12$ & $256 \pm 21^{*}$ & $596 \pm 74$ & $247 \pm 11^{*}$ & $584 \pm 32$ & $180 \pm 6^{*} \ddagger \S$ \\
\hline Villus cell size $(\mu m)$ & $5.4 \pm 0.1$ & $5.3 \pm 0.4$ & $8.2 \pm 0.9 \ddagger$ & $5.7 \pm 0.2^{*}$ & $8.6 \pm 0.4 \ddagger$ & $3.9 \pm 0.1 * \ddagger \S$ \\
\hline Cells/villus $(n)$ & $154 \pm 8$ & $71 \pm 2^{*}$ & $92 \pm 9 \ddagger$ & $97 \pm 6 \ddagger$ & $100 \pm 5 \ddagger$ & $90 \pm 4 \ddagger$ \\
\hline Villi/millimeter in serosal length $\mathrm{A}(n)$ & $7.0 \pm 0.3$ & $10.1 \pm 0.7^{*}$ & $7.4 \pm 0.5$ & $6.8 \pm 0.7 \ddagger$ & $9.0 \pm 0.5 \ddagger$ & $7.9 \pm 0.3 \ddagger$ \\
\hline Villi/millimeter in serosal length B $(n)$ & $2.6 \pm 0.1$ & $2.4 \pm 0.1$ & $2.0 \pm 0.2 \ddagger$ & $4.4 \pm 0.4 \ddagger$ & $2.3 \pm 0.2 \ddagger$ & $3.0 \pm 0.2^{*} \ddagger \S$ \\
\hline Villi/square millimeter of serosa $(n)$ & $18 \pm 1$ & $23 \pm 2^{*}$ & $14 \pm 1$ & $28 \pm 3^{*}$ & $18 \pm 1 \ddagger$ & $23 \pm 1^{*}$ \\
\hline \multicolumn{7}{|l|}{ Mucosal surface area } \\
\hline$\left(\mathrm{mm}^{2} / \mathrm{mm}^{2}\right.$ serosa $)$ & $8.8 \pm 0.5$ & $5.9 \pm 0.4^{*}$ & $8.3 \pm 1.2$ & $7.0 \pm 0.9$ & $11.0 \pm 1.00$ & $4.1 \pm 0.20^{*} \ddagger \S$ \\
\hline
\end{tabular}

${ }^{*} P<0.05$, jejunum vs. ileum. $\ddagger P<0.05$, Chow vs. HP, or Chow vs. HS. $\S P<0.05$, HP vs. HS. 

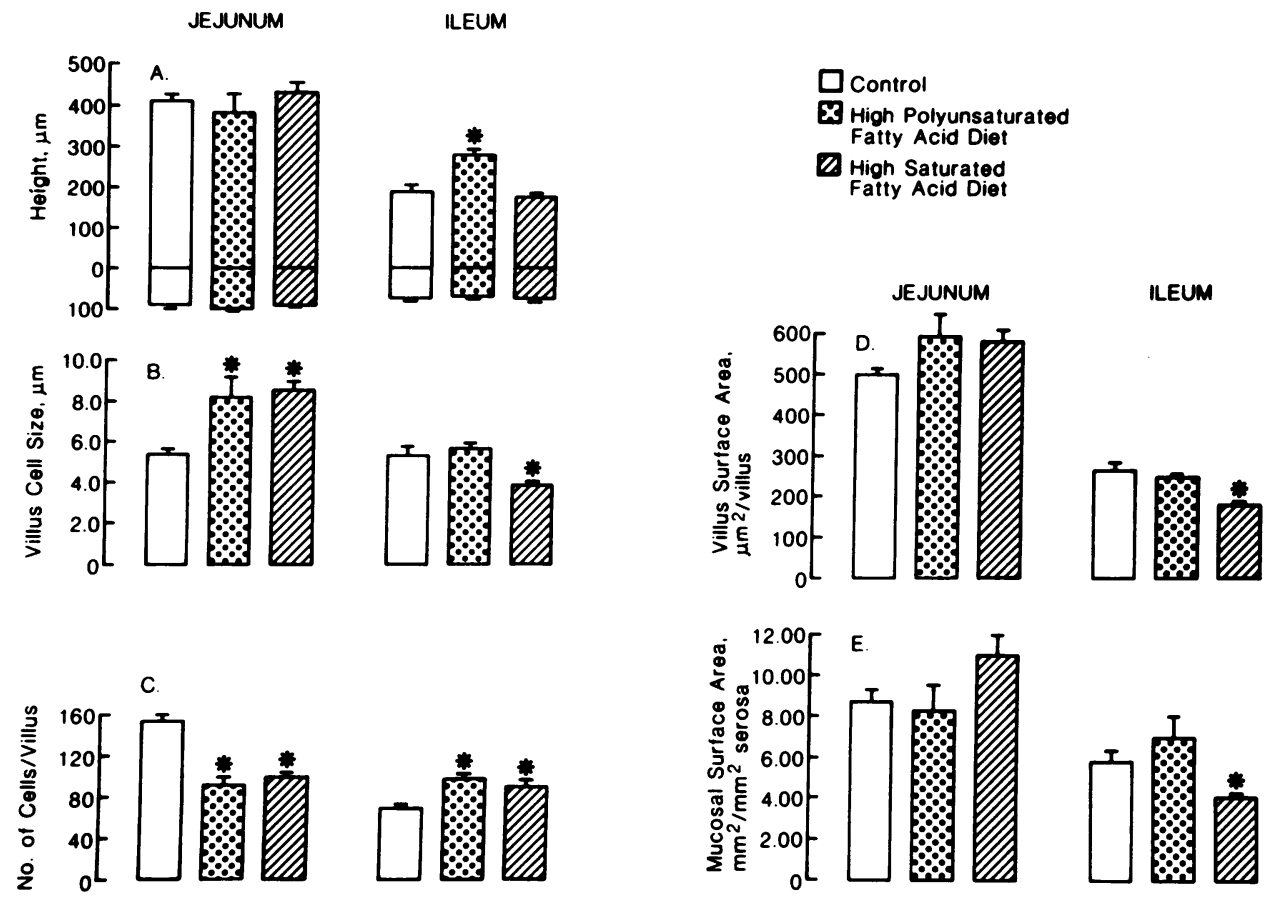

Figure 8. Effect of fatty acid composition of the diet on intestinal morphology. An asterisk (*) indicates that the difference between the semisynthetic and the control chow diet was statistically significant, $P<0.05$.

thetic diet (Fig. 6), the jejunal uptake of glucose was lower, whereas the ileal uptake of leucine was higher in animals fed HS as compared with HP (Fig. 5 and 7). Previously it has been suggested that there may be at least two intestinal carriers for glucose and for galactose (40). The differential effect of diet on the uptake of glucose and of galactose supports this suggestion, although the possible effect of HS on the intestinal metabolism of glucose was not examined in this study. A differential effect of the manipulation of the dietary content of protein and carbohydrate on the uptake of glucose, 3-O-methyl glucose and proline into jejunal and ileal mouse intestinal sleeves has been reported recently (41). The different patterns of uptake of glucose and leucine in the jejunum as compared with the ileum (Fig. 5 and 7) suggests that the diets produced a local effect in the proximal versus the distal small intestine. The lack of difference in jejunal uptake of leucine in rats fed the semisynthetic diets, yet the higher ileal uptake of leucine in animals fed the HS (Fig. 7) raise the possibility of a systemic effect of the diets on the control of intestinal absorption.

The jejunal morphology was not significantly altered by the semisynthetic diets (Table VIII), but feeding HP abolished the morphologic differences between the ileum and the jejunum observed in animals fed Chow or HS. The saturated fatty acid content of the diet did influence the morphology of the ileum, with a lower villus and mucosal surface area (Fig. 8). The lack of correlation between the altered jejunal transport and villus morphology argues against the functional changes as being due to an alteration in the form of the intestine. However, it remains unclear what is the signal by which dietary saturation of fat influences ileal morphology. Do the saturated fatty acids suppress ileal mucosal surface area, or do the polyunsaturated fatty acids stimulate the ileum to become morphologically more like the jejunum? It is possible that some of these relatively small differences in morphology simply reflect the fact that different amounts of each lipid was reaching different areas of the bowel because the animals were eating different amounts of fatty acids and because the fatty acids were absorbed at different locations along the length of the intestine.

In summary, small changes in the fatty acid composition of the diet influence the intestinal uptake of passively and actively transported solutes. These diet-related effects could be brought about by a change in the morphology of the gut, a change in the chemical composition of the BBM, a change in the function of carrier proteins, or a change in the characteristics of the outer diffusion barriers. In the jejunum, villus morphology did not change (Table VIII and Fig. 8). Although unstirred layer resistance did change in response to dietary manipulation (Fig. 4), it did not change in the amount or in the direction appropriate to explain the increased uptake of cholesterol, CDCA, TCDCA, FA 10:0, FA 12:0, FA 16:0, FA 18:0, and FA 18:2 in animals fed the high saturated fatty acid diet (Figs. 2-4). The cholesterol and phospholipid content of the brush border was unaffected by the dietary content of fatty acid (Tables VI and VII). However, we did not measure BBM fluidity on the fatty acyl content of the phospholipids. Although caution should be used in inferring changes in membrane fluidity based on lipid modulation (7), diet-related changes in the BBM content of 18:1, 18:2, and 20:4 have recently been described (6). Although a more fluid membrane associated with the feeding of polyunsaturated lipids would mean higher membrane mobilities and higher rates of active transport (as was observed for glucose uptake into the jejunum, (Fig. 5), a higher membrane mobility would not be expected to be associated with lower rates of uptake of fatty acids, cholesterol, bile acids, or leucine (Fig. 2-7). Thus, although it is feasible to modulate intestinal transport function in vivo by means of dietary manipulation, the mechanism by which these changes occur remains an enigma.

\section{Acknowledgments}

The authors wish to express their appreciation for financial support from the Medical Research Council (Canada), and from the Alberta Heritage 
Foundation for Medical Research for funds to purchase the scintillation counter and centrifuges used in this study.

\section{References}

1. Clandinin, M. T., C. J. Field, K. Hargreaves, L. A. Morson, and E. Zsigmond. 1985. Role of diet in subcellular structure and function. CFBS Symposium Lecture. Can. J. Physiol. Pharmacol. 63:546-556.

2. Thomson, A. B. R. 1982. Influence of dietary modifications on uptake of cholesterol, glucose, fatty acids and alcohols into rabbit intestine. Am. J. Clin. Nutr. 35:556-565.

3. Thomson, A. B. R., and R. Rajotte. 1983. Effect of dietary modifications on the enhanced uptake of cholesterol in diabetic rats. Am. J. Clin. Nutr. 37:244-252.

4. Thomson, A. B. R., and R. Rajotte. 1983b. Effect of dietary modifications on the enhanced uptake of glucose, fatty acids and alcohols in diabetic rats. Am. J. Clin. Nutr. 38:394-403.

5. Kritchevsky, D., L. M. Davidson, and I. L. Shapiro. 1974. Lipid metabolism and experimental atherosclerosis in baboons: influence of cholesterol-free, semisynthetic diets. Am. J. Clin. Nutr. 27:29-50.

6. Brasitus, T. A., N. O. Davidson, and D. Schachter. 1985. Variations in dietary triacylglycerol saturation alter the lipid composition and fluidity of rat intestinal plasma membranes. Biochim. Biophys. Acta. 812:460472.

7. Di Costanzo, G., G. Duportail, A. Florentz, and C. Leroy. 1983. The brush border membrane of trout intestine: influence of its lipids composition on ion permeability, enzyme activity and membrane fluidity. Mol. Physiol. 4:279-290.

8. Lukie, B. E., H. Westergaard, and J. M. Dietschy. 1974. Validation of a chamber that allows measurement of both tissue uptake rates and unstirred layer thickness in the intestine. Gastroenterology. 67:652-661.

9. Thomson, A. B. R. 1980. Unidirectional flux rate of cholesterol and fatty acids into the intestine of rats with drug-induced diabetes mellitus: effects of variations in the effective resistance of the unstirred water layer and the bile acid micelle. J. Lipid Res. 21:687-698.

10. Westergaard, H., and J. M. Dietschy. 1974. Delineation of the dimensions and permeability coefficients of the two major diffusion barriers to passive mucosal uptake in the rabbit intestine. J. Clin. Invest. 54:718-732.

11. Westergaard, H., and J. M. Dietschy. 1976. The mechanism whereby bile acid micelles increase the rate of fatty acid and cholesterol uptake into the intestinal mucosal cell. J. Clin. Invest. 58:97-108.

12. Yakymyshyn, L. M., K. Walker, and A. B. R. Thomson. 1982. Use of Percoll ${ }^{\circ}$ in the isolation and purification of rabbit small intestinal brush border membranes. Biochim. Biophys. Acta. 690:269-281.

13. Lowry, O., N. Rosebrough, A. Farr, R. J. Randall. 1951. Protein measurement with the Folin phenol reagent. J. Biol. Chem. 193:265275.

14. Dahlqvist, A. 1964. Method for assay of intestinal disaccharidases. Anal. Biochem. 7:18-25.

15. Bowers, G. N., M. L. Kelly, and R. B. McComb. 1967. Continuous spectrophotometric measurement of alkaline phosphatase activity. Clin. Chem. 13:608-610.

16. Glaser, J. H., and W. S. Sly. 1973. $\beta$-Glucuronidase deficiency mucopolysaccharidases: methods for enzymatic diagnosis. J. Lab. Clin. Med. 82:969-979.

17. Burton, K. 1956. A study of the conditions and mechanism of the diphenylamine reaction for the colorimetric estimation of deoxyribonucleic acid. Biochem. J. 62:315-323.

18. Giles, K. W., and A. Myers. 1965. An improved diphenylamine method for the estimation of deoxyribonucleic acid. Nature (Lond.). 206:93.

19. Bowyer, D., and J. King. 1977. Methods for the rapid separation and estimation of the major lipids of arteries and other tissues by thin- layer chromatography on small plates followed by microchemical assays. J. Chromatogr. 143:473-495.

20. Folch, J., M. Lees, and G. Stanley. 1957. A simple method for the isolation and purification of total lipids from animal tissues. J. Biol. Chem. 226:497-509.

21. Mizuno, K., M. Toyosato, S. Yabumoto, I. Tanimizo, and H. Hirakawa. 1980. A new enzymatic method for colorimetric determination of free fatty acids. Anal. Biochem. 108:6-10.

22. Okabe, H., Y. Uji, K. Nagashima, and A. Noma. 1980. Enzymatic determinations of free fatty acids in serum. Clin. Chem. 26:1540-1543.

23. Osuga, T., K. Mitamura, F. Mashige, and K. Imai. 1977. Evaluation of fluorimetrically estimated serum bile acid in liver disease. Clin. Chim. Acta. 75:81-90.

24. Mashige, F., K. Imai, and T. Osuga. 1976. A simple and sensitive assay of total serum bile acids. Clin. Chim. Acta. 70:79-86.

25. Allain, C. C., L. S. Poon, C. S. G. Chan, W. Richinond, and P. C. Fu. 1974. Enzymatic determination of total serum cholesterol. Clin. Chem. 20:470-475.

26. Morin, R. J. 1976. Rapid enzymatic determination of free and esterified cholesterol content of serum and tissues. Clin. Chim. Acta. 71: 75-80.

27. Sunderman, F. W., and R. N. Sunderman, Jr. 1960. Lipids and Steroid Hormones in Clinical Medicine. J.B. Lippincott Co., Philadelphia. Ch. 5.28.

28. Freeman, C. P., and D. West. 1966. Complete separation of lipid classes on a single thin-layer plate. J. Lipid Res. 7:324-327.

29. Vitiello, F., and J. P. Zanetta. 1978. Thin-layer chromatography of phospholipids. J. Chromatogr. 166:637-640.

30. Ecknauer, R., T. Vadakel, and R. Wepler. 1982. Intestinal morphology and cell production rate in aging rats. J. Gerontol. 37:151-155.

31. Schiff, E. R., N. C. Small, and J. M. Dietschy. 1968. Characterization of the kinetics of the passive and active transport mechanisms for bile acid absorption in the small intestine and colon of the rat. $J$. Clin. Invest. 51:1351-1362, 1972.

32. Thomson, A. B. R., and J. M. Dietschy. 1981. Intestinal lipid absorption: major extracellular and intracellular events. In Physiology of the Gastrointestinal Tract. Chapter 46. L. R. Johnson, editor. Raven Press, New York. 1147-1220.

33. Winne, D. 1978. The permeability coefficient of the wall of a villous membrane. J. Math. Biol. 6:95-108.

34. Morin, C. L., V. Ling, and M. Van Caillie. 1978. Role of oral intake on intestinal adaptation after small bowel resection in growing rats. Pediatr. Res. 12:268-271.

35. Boggs, J. M. 1980. Intermolecular hydrogen bonding between lipids: influence on organization and function of lipids in membranes. Can. J. Biochem. 58:755-770.

36. Chapman, D. 1975. Phase transitions and fluidity characteristics of lipids and cell membranes. Q. Rev. Biophys. 8:185-235.

37. Foot, M., T. F. Cruz, and M. T. Clandinin. 1982. Influence of dietary fat on the lipid composition of rat brain synaptosomal and microsomal membrane. Biochem. J. 208:631-640.

38. Innis, S. M., and M. T. Clandinin. 1981. Dynamic modulation of mitochondrial inner-membrane lipids in rat heart by dietary fat. Biochem. J. 193:155-167.

39. Thomson, A. B. R., and J. M. Dietschy. 1984. The role of the unstirred water layer in intestinal permeation. In Pharmacology of Intestinal Permeation. Vol. 2. Chapter 21. T. Z. Csaky editor. SpringerVerlag, New York. 165-269.

40. Honnegar, P., and G. Semenza. 1973. Multiplicity of carriers for free glucalogues in hamster small intestine. Biochim. Biophys. Acta. 318: 390-410.

41. Diamond, J. M., and W. H. Karasov. 1984. Effect of dietary carbohydrate on monosaccharide uptake by mouse small intestine in vitro. J. Physiol. (Lond.). 349:419-440. 